\title{
Employee Blogs: Protected Speech Or Grounds For Discharge?
}

Claire R. La Roche, (Email: larochecr@longwood.edu), Longwood University Glenn S. Dardick, (Email: dardickgs@longwood.edu), Longwood University Mary A. Flanigan, (Email: flaniganma@longwood.edu), Longwood University

\begin{abstract}
Posting and reading blogs is one of the fastest growing uses of the Web. Blogging gives an ordinary person the ability to have a conversation with a wide audience. Dozens of employeebloggers have been "dooced" (terminated) for exercising what they consider to be their First Amendment right to free speech. An important legal issue with significant implications for both employers and employees is to what extent are employee blogs a form of protected speech. The First Amendment, employment at will, and laws protecting employee speech are discussed. Suggestions are made for procedures employees should follow to safely blog.
\end{abstract}

\section{INTRODUCTION}

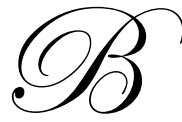

logging or keeping a weblog or online journal is one of the fastest growing uses of the Internet. Although most employers have an Internet and/or an e-mail policy, blogging is not typically addressed in these policies. Consequently, many employees assume that the First Amendment right to free speech protects their right to post a blog and by extension will protect their job, particularly if they are not blogging at work or even about work. This assumption could not be farther from the truth. The number of bloggers being fired for sharing their thoughts and perceptions continues to increase. In a 2007 Proofpoint Inc. survey of 308 U.S. companies with 1,000 or more employees, $9.1 \%$ of companies surveyed terminated employees for blog or message board postings within the past 12 months (Proofpoint, Inc., 2007).

Blogs are informal and frequently posted without due reflection or thought as to the appropriateness of the contents. There appears to be a tendency to reveal information or express thoughts in a blog that one would be reluctant to say in person or in a traditional print medium, particularly if the blogger believes that s/he is blogging anonymously. Two important legal questions with significant implications for both employers and employees are: 1) Do employees have a First Amendment right to blog without fear of retribution? 2) What types of speech are protected?

\section{POWER OF THE BLOG}

Bloggers have the potential to reach millions of readers. Kryptonite Lock Company, manufacturer of casehardened U-locks, was shocked by the power of the blog in September, 2004. The company was caught in a blogstorm initiated by a consumer who discovered that he could unlock his Kryptonite lock with the empty barrel of a ball point pen and posted a short video clip picking a Kryptonite U-lock (Lewis, 2004). This incredible story grew in the blogoshere and decimated Kryptonite's sales. Ultimately, the story was picked up by the N.Y Times (Pohlgreen, 2004) and other newspapers.

In 2006, Time Magazine's Person of the year was "You". In part, bloggers and the new uses of the Web were responsible for the choice. According to Time's explanation, the Web has been revolutionized and is being used as "a tool for bringing together the small contribution of millions of people and making them matter" (Grossman, 2006). Time sees the Web as "an opportunity to build a new kind of international understanding, not politician to politician, great man to great man, but citizen to citizen, person to person. It's a chance for people to look at a computer screen and really, genuinely wonder who's looking back at them.” (Grossman, 2006) 
Recent surveys conducted by the Pew Internet \& American Life Project indicate that approximately 39\% of adults in the U.S. read blogs and 8\% of Americans participate in this form of personal publishing (Lenhart and Fox, 2006). The chart below shows the exponential increase in blog creation and readership from 2004 to 2006.

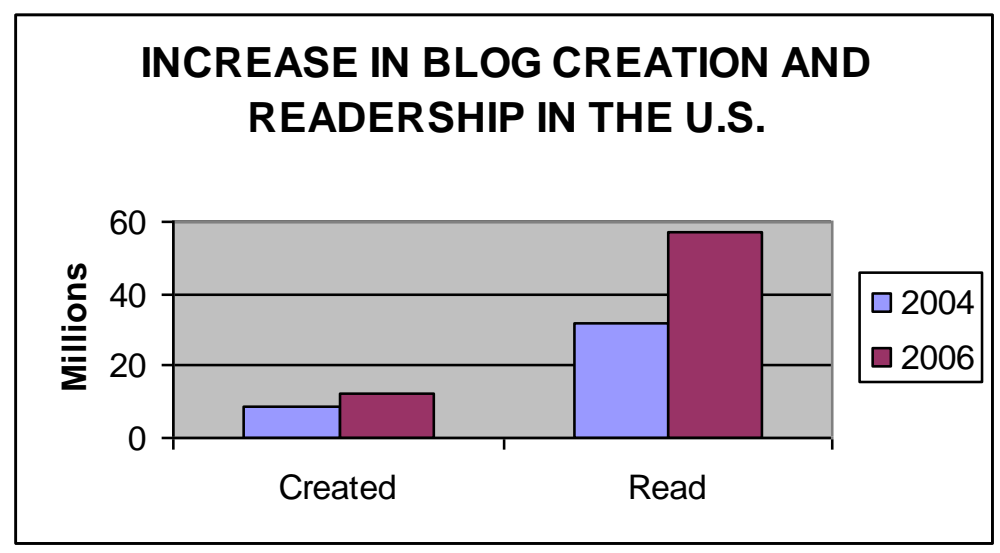

Source: Pew Internet and American Life Project

\section{UNEXPECTED CONSEQUENCES}

Many bloggers mistakenly believe that their blog will not be seen by employers. For instance, Matthew Brown, a former Starbucks supervisor in Toronto, used his blog to keep in touch with his family and friends. In one posting, Brown mentioned that his supervisor did not let him go home when he was sick. The day before he was to begin management training, Brown was fired based on the posting about his supervisor. Brown, to this day, does not know how the blog got into the hands of his boss (Koulouras, 2004).

Blogging is by definition a public activity. Thus, there is virtually no reasonable expectation of privacy. Search tools such as Google's Blog Search and Really Simple Syndication (RSS) feeds have made it easier to find and read specific blog content. Brown isn't the only blogger to learn the hard way that the person you don't think will read your blog will find it and read it. According to Heather Armstrong, the original "dooced" employee, "They specifically will find it and read it, and all hell will break loose." (Witt, 2004) In 2002, Armstrong was fired from dooce.com when her employer found the contents of her blog to be offensive.

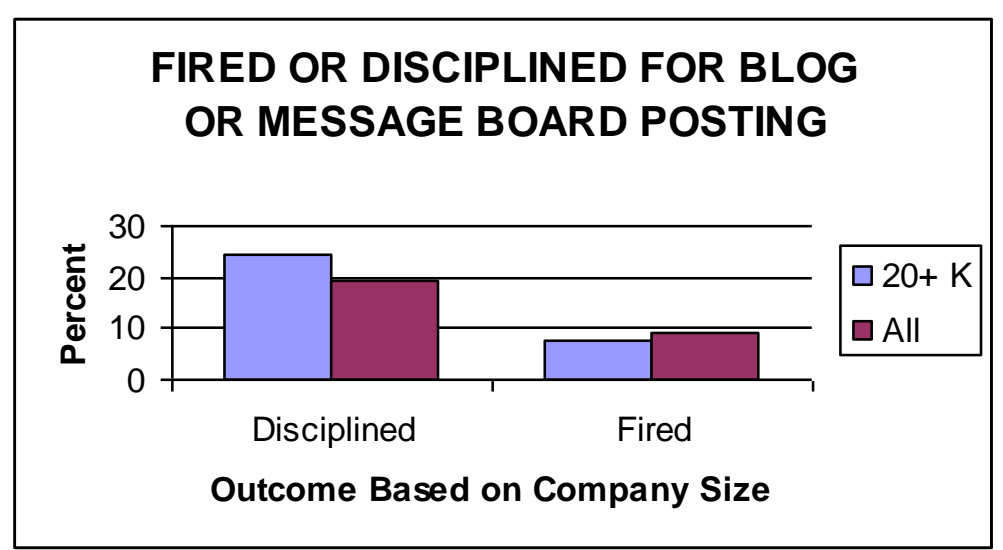

Source: Proofpoint, Inc. Outbound Email and Content Security in Today's Enterprise, 2007 Survey 
According to the 2007 Proofpoint survey, approximately 1 in 10 companies surveyed reported that they had fired an employee and greater than 1 in 5 companies have disciplined an employee for blogging or message board postings.

Although there is a dearth of case law involving employees wrongfully terminated for blogging, dozens of employees who have been dismissed based on the contents of their blogs have shared their stories on the Internet. Cameron Barrett is considered to be one of the pioneer bloggers. By all accounts, Barrett was the first blogger to be terminated as a result of the contents of his blog. In 1997, Barrett was employed at a small marketing firm in Northern Michigan and casually mentioned that he had his own website. Two of the female employees looked at Barrett's website and after reading some of his experimental fiction posted online told their employer that "Either he goes, or we go." (Barrett) According to Barrett, he never used his employer's time or equipment to write his blog and never told his co-workers to read his stories (Barrett).

Ellen Simonetti was terminated by Delta as a result of the contents of her blog. Simonetti was a flight attendant for Delta and posted photos revealing her cleavage while dressed in her uniform. As soon as Simonetti's supervisor expressed his displeasure, she took down the offensive photographs. Without any further notice, Simonetti was placed on leave and fired three weeks later (Simonetti, 2004).

Michael Hanscom, an employee for Microsoft was fired in 2003 for posting photos of Apple computers on a Microsoft loading dock that was visible from a public road. Hanscom labeled the photo with the caption "Even Microsoft wants G5s". (Bonné, 2003) According to Hanscom, "I was told that they saw it as a security violation...I think they might have seen it as derogatory." (Bonné, 2003)

Although the blogging phenomenon has promoted the development of social networks such as Friendster, Joyce Park, a web designer for the company, learned the hard way that Friendster did not appreciate her blog comments. Park was hired by Friendster to rewrite the Friendster website in PHP. According to Park, her primary offense was to refer to the former programming language used at Friendster as being "pokey". "I only made three posts about Friendster on my blog before they decided to fire me, and it was all publicly available information. They did not have any policy, didn't give me any warning, they didn't ask me to take anything down." (Olsen, 2004)

\section{IS A BLOG PROTECTED SPEECH?}

According to the most recent Pew American Life \& Internet Project survey, only 7\% of bloggers admit to "usually blogging at work" (Lenhart and Fox). When employee blogs are created outside of work and are not defamatory in nature, does the First Amendment protect their right of free speech and by extension, their jobs? The First Amendment restricts government control of speech by providing that "Congress shall make no law..." that abrogates our right of free speech. It specifically protects citizens from government restrictions and censorship; however, it does not protect an employee from the unwanted consequences of that speech. Employees are often shocked when they are disciplined or even discharged for their personal blogs created at home based on the assumption that the First Amendment right of free speech protects them from retaliation for posts that the employer finds offensive.

To date, there are only five states that have enacted laws that protect employees from being discharged as a result of off-duty activities and they are: California, New York, North Dakota, Montana, and Colorado (Gilbert, 2005). The vast majority of states follow the common law "employment at will" doctrine. As a general rule, this doctrine provides that if an employee is not working under a contract with a set duration, he/she may be fired for any reason, or without cause, provided that a law or an established public policy has not been violated. For the most part, the employment at will doctrine outweighs an individual's right of free speech.

Some bloggers assume that the legal shield protecting "whistleblowers" also applies to bloggers who are writing about work conditions that have the potential of being reported to a regulatory agency such as OSHA. Unfortunately, this too, is a risky assumption. In many instances, whistleblowers are only protected from employer 
retaliation if they file a complaint in the traditional way with the appropriate state or federal agency -- before blogging about the complaint (EFF: Legal Guide for Bloggers, 2006).

There is some limited protection for bloggers in the form of statutory or judicial doctrines and through provisions in contracts of employment. The National Labor Relations Act 29 U.S.C. §157, protects employees trying to unionize as well as those who "engage in other concerted activities for the purpose of collective bargaining or other mutual aid or protection.". Additionally, a majority of states (26) shield political bloggers from employer retaliation with Anti-SLAPP (Strategic Lawsuit Against Public Participation) laws protecting employees' political activities. Anti-SLAPP laws are generally intended to guarantee the exercise of free speech and the right of all citizens to petition the government. Many of these statutes also provide immunity from strategic lawsuits aimed at limiting political participation (California Anti-SLAPP Project).

\section{SHADOW BLOGGING}

To avoid unwanted identification, a blogger may wish to remain anonymous. Blogging safely from the shadows is possible, but needs to be done with care. Anonymity on the Internet requires a multi-pronged approach. A blogger desiring anonymity might hide "where" they are, but the anonymity is moot if visitors to the blog know "Who" the blogger is. Anonymity can also be compromised if certain details are divulged such as the equipment (the "What") that the blogger is using via details of their system made available by their accessing the blog site.

- Where a blogger is located can be determined by knowing a number (IP address) that is assigned to the computer being used by the blogger to access the blog via the Internet. When a blogger, or for that matter any Internet user, accesses a website, such as one hosting a blog, details are recorded at the website, such as the user's IP address. A blogger can keep their IP address anonymous by providing a different IP address to the website. This is typically done by going through an intermediary on the Internet referred to as a proxy. Proxies may be used to access other proxies. Proxies may be referenced by proxy systems such as Tor (Tor). The Tor proxy system maintains an inventory of available proxies on the Internet. Proxies such as those used by Tor are randomly selected from around the world. Such proxies are provided voluntarily by users of the Tor system and are typically used in chains of three - one proxy going through another proxy going through yet another proxy.

- What a blogger uses to access the blog via the Internet is passed through the Internet via "Headers". Headers are transferred between computer browsers and website servers when website pages are accessed. A header is a record containing specific types of information, such as the type of operating system being used and the type of browser being used. Other information may be gathered from the blogger's system if certain code is allowed to run within the browser. Such code is typically run with "Scripts" contained within web pages. To avoid passing information that might identify details of, or from, the bloggers system, communications from the blogger's system, such as headers, can be dynamically altered via proxies capable of filtering such information. Potential threats from the code within scripts can also be blocked via the use of filters from such proxies. Filters are capable of changing or completely removing code which can compromise a system's and/or blogger's identity. Filtering capability is provided by proxy products such as Privoxy (Privoxy).

- Who the blogger is may be divulged through payment and/or registration records. If a blogger uses their credit card or real name in paying for, or registering a website or e-mail address, then their identity is at risk of being exposed. However, a blogger can easily find blogging sites already available which will maintain the blogger's anonymity. E-mail addresses can also be obtained that provide anonymity to the blogger, as long as care is exercised when accessing such systems as mentioned previously - such as with the use of systems like Tor and Privoxy.

Achieving anonymity through the use of proxies as suggested above is accomplished by installing software that is readily available on the Internet (Privoxy, Tor Download, Torbutton, Vidalia). Vidalia is actually not a necessary program to maintain anonymity, but is useful as an easy to use interface to the Tor system. Torbutton, like Vidalia, is not necessary, but is used with the Firefox (Firefox) web browser in allowing easy access to enabling and 
disabling Tor usage. Much of the software is available for free and available as downloads from the Internet. There is also plenty of advice, recommendations and support readily available via the Internet from organizations and individual websites (Electronic Frontier Foundation (2005), Morris (2005), Zuckerman (2005)).

\section{CONCLUSION}

Due to the informal and often therapeutic nature of this form of communication, bloggers may post personal thoughts, photos, and work-related comments without giving much thought to the contents. Many bloggers post tell-all entries that have a tendency to conflict with their employer's expectations. Any time an entry is posted, the blogger should assume that the person(s) it is not intended for will find it and it will be forwarded. Some suggestions for safe blogging include the following:

- $\quad$ Always tell the truth when blogging.

- $\quad$ Common sense should be exercised before an item or picture is posted on the Web.

- $\quad$ Once something is posted in the Internet, it will always exist and thus, tell-all blogging should be avoided. Information a blogger is willing to reveal today, may cause embarrassment tomorrow.

- $\quad$ To decrease the possibility of embarrassment or termination, blog anonymously by using a pseudonym and employ shadow blogging.

Considering the potential for a blogger to reach millions of readers, employers should implement a blogging policy that clearly delineates the boundaries of employee conduct. This policy should notify employees that blogging is not permitted at work. Furthermore, the policy should provide that messages containing defamatory, unprofessional, discriminatory, or obscene content are inappropriate and actionable. The manner in which employees will be disciplined for violating the policy should also be outlined.

Although there is a dearth of case law specifically involving bloggers, the majority of states follow the employment at will doctrine and thus, most non-union employees may be terminated without cause. What one blogger considers informative, funny, or therapeutic, is often objectionable to someone else. Before posting a blog, careful consideration should be given to both the contents and the potential ramifications.

\section{REFERENCES}

1. Barrett, Cameron, How Cameron Got Screwed. http://www.camworld.com/screwed (accessed 9/27/2007).

2. Bonné, Jon (2003) Blogger dismissed from Microsoft, MSN.com, http://www.msnbc.msn.com/id/3341689/print/1/displaymode/1098/ (accessed September 6, 2007).

3. California Anti-SLAPP Project, http://www.casp.net/menstate.html (accessed July 31, 2007).

4. $\quad$ EFF: Legal Guide for Bloggers (2006), http://www.eff.org/bloggers/lg/ (accessed July 31, 2007).

5. Electronic Frontier Foundation (2005) http://tor.eff.org/eff/tor-legal-faq.html.en (accessed September 5, 2007).

6. Firefox http://www.mozilla.com/en-US/firefox/ (accessed September 5, 2007).

7. Gilbert, Alorie (2005), FAQ: Blogging on the job cnet NEWS.COM, http:news.com.com/2102-1030_35597010.html?tag=st.util.print (accessed July 31, 2007).

8. Grossman, Lev (2006), Time's Person of the Year: You, TIME http://www.time.com/time/magazine/article/0,9171,1569514,00.html

9. Koulouras, Jason (2004) Employee fired by Starbucks over Blog, Blogcritics magazine, http://blogcritics.org/archives/2004/09/04/141004.php (accessed July 29, 2007).

10. Lenhart, Amanda, Fox, Susannah (2006) Bloggers A portrait of the Internet's new storytellers, Pew Internet \& American Life Project, July 19, 2006.

11. Lewis, Mike (2004), All it takes is a Bic to pick popular bike locks, Seattle Post-Intelligencer Reporter, http://seattlepi.nwsource.com/local/191201_bikelocks17.html?source=rss (accessed September 5, 2007).

12. Morris, Sofia (2005), An Anonymous Blogger Tells All, http://journalism.nyu.edu/pubzone/notablog/story/anonymous/ (accessed September 5, 2007). 
13. Olsen, Stefanie (2004), Friendster fires developer for blog c/net news.com, http://new.com.com/21021038 3-5331835.html?tag=st.util.print (accessed 7/29/2007).

14. Polgreen, Lydia (2004), The Pen Is Mightier Than the Lock, The New York Times, http://www.nytimes.com/2004/ 09/17/yregion/17lock.html

15. Privoxy http://www.privoxy.org/ (accessed September 5, 2007).

16. Proofpoint, Inc. (2007) Outbound email and Content Security in Today's Enterprise www.proofpoint.com

17. Simonetti, Ellen (2004), I was fired for blogging, CNET News.com, http://news.com.com/I+was+fired+for+blogging/2010-1030_3-5490836.html

18. Tor http://tor.eff.org/overview.html.en (accessed September 5, 2007).

19. Tor Download http://tor.eff.org/download.html.en (accessed September 5, 2007).

20. Torbutton http://freehaven.net/ squires/torbutton/ (accessed September 5, 2007).

21. Vidalia http://vidalia-project.net/index.php (accessed September 5, 2007).

22. Witt, April (2004), Blog Interrupted, Washington Post, August 15, 2004, p. W12.

23. Zuckerman, Ethan (2005) Global Voices http://www.globalvoicesonline.org/?p=125 (accessed September 5, 2007).

\section{NOTES}

